\title{
Diversidad específica bacteriana en murciélagos de distintos gremios alimenticios en la sierra sur de Oaxaca, México
}

Mónica Marcela Galicia J. ${ }^{*}$, Alejandra Buenrostro S. ${ }^{2} \&$ Jesús García G. ${ }^{3}$

1. Instituto de Genética. Universidad del Mar. Campus Puerto Escondido. Ciudad Universitaria, Carretera Vía Sola de Vega, Puerto Escondido, San Pedro Mixtepec, Juquila, Oaxaca, México C.P. 71980; monicagalicia@zicatela.umar.mx

2. Instituto de Industrias, Universidad del Mar. Campus Puerto Escondido. Ciudad Universitaria, Carretera Vía Sola de Vega, Puerto Escondido, San Pedro Mixtepec, Juquila, Oaxaca, México C.P. 71980; sba_1575@yahoo.com.mx

3. Instituto de Recursos, Universidad del Mar. Campus Puerto Escondido. Ciudad Universitaria, Carretera Vía Sola de Vega, Puerto Escondido, San Pedro Mixtepec, Juquila, Oaxaca, México C.P. 71980; archosaurio@yahoo.com.mx

* Correspondencia

Recibido 28-I-2014. Corregido 20-VI-2014. Aceptado 21-VII-2014.

\begin{abstract}
Specific bacterial diversity in bats of different food guilds in Southern sierra Oaxaca, Mexico. Bats have different ecologic roles in variable ecosystems that have been already described. They have been linked to several zoonoses, however little is known about the relationship between bat microbiota and their diet, and studies on the bacterial ecology of the microbiota in bats are limited. To contribute with the description of this important interaction between microbiota and host, the aim of this work was to characterize the composition and bacterial diversity in the oral and anal regions of 10 species of bats, in relation to food guild. For this, monthly samplings were conducted using four mist nets (19:00-24:00h) from February to October 2012; nets were reviewed every 45 minutes. Each captured organism was sampled in the oral and anal cavities with sterile swabs; these were placed in pre-enrichment media and stored at $4^{\circ} \mathrm{C}$. Bacterial samples were studied which through selective media, chromogenic and biochemical tests. We obtained samples from 502 frugivorous, 29 hematophagous and 11 nectivorous bats. We found a total of 26 bacterial species, with the predominant phylum Proteobacteria and the family Enterobacteriaceae. Statistically significant differences were observed between oral and anal microhabitats: frugivorous $(\mathrm{t}=-3.516$, g. $\mathrm{l}=14.761, \mathrm{p}=0.003)$, hematophagous $(\mathrm{t}=-3.320$, g.l $1=19.262$, $\mathrm{p}=0.003)$, and nectivorous $(\mathrm{t}=-2.497, \mathrm{~g} . \mathrm{l}=11.933, \mathrm{p}=0.026)$, and in some guilds [frugivorous and nectivorous in the anal region $(\mathrm{t}=2.274, \mathrm{~g} . \mathrm{l}=29.660, \mathrm{p}=0.030)$, hematophagous and nectivorous anal region $(\mathrm{t}=2.077$, g.l $=29.904, \mathrm{p}=0.049)$ ]. It was also shown that there is bacteria specificity in some guilds such as nectivorous and frugivorous with Bacillus cereus, B. sp. X. sp., as well as, Pseudomonas aeruginosa, Serratia marcescens, Staphylococcus aureus, S. epidermis, Aeromonas hydrophyla in hematophagous. Bacterial presence can be explained by the type of diet and/or by transfer of bacteria from their preys. These bacteria may be indigenous to these bats and play the role of mutual benefit, providing the host with stable growth conditions and supplemental nutrients, while the microbiota contributes to host nutrition, development of the immune system, stabilization of the microbial population and to avoid pathogens colonization. By understanding the importance of the relationship between host and its bacterial populations, the conservation efforts being made to protect species such as bats may be improved. Rev. Biol. Trop. 62 (4): 1673-1681. Epub 2014 December 01.
\end{abstract}

Key words: bats, frugivorous, hematophagous, nectivorous, bacterial diversity, microbiota.

La relación entre los macroorganismos y su microbiota son influenciados por muchos factores, incluyendo la especificidad del hospedero y la composición del alimento (Jablonski, 1979), sin embargo, el conocimiento básico sobre la microbiota en mamíferos de vida silvestre es insuficiente (Souza, Rocha, Valera, \& Eguiarte, 1999), y los murciélagos no son la excepción.

Los quirópteros representan el segundo orden más diverso de los mamíferos después de los roedores (Kunz \& Brock, 2006), son un 
grupo importante para caracterizar la diversidad biológica en un área. Incluso juegan un papel ecológico fundamental por su participación en múltiples interacciones ecológicas debido principalmente a la gran variedad en sus hábitos alimenticios (insectívoros, nectarívoros, frugívoros, carnívoros y hematófagos), que por añadidura, les permite ser depredadores, presas e importantes polinizadores y dispersores de semillas (Chaverri, 2006; Kunz \& Brock, 2006).

Algunos reportes han documentado la existencia de una relación simbiótica muy estrecha entre los murciélagos y una gran cantidad de microorganismos (Whitaker, Dannelly Jr., \& Prentice, 2004; Voigt, Caspers, \& Speck, 2005); no obstante, existe poco conocimiento sobre la interacción, la influencia y el papel ecológico de la microbiota en cavidad oral y anal de los quirópteros, a pesar de la importancia que tienen, tales como: en la degradación y digestión de alimentos que éstos ingieren, en la síntesis de ciertas vitaminas, y en la protección que les da contra otros microorganismos dañinos (Klite, 1965; Moreno, Lopes, Seabra, Pavan, \& Correa, 1975; Pinus \& Müller, 1980; Di Bella et al., 2003; Whitaker et al., 2004; Chaverri, 2006; Mühldorfer, Wibbelt, Haensel, Riehm, \& Speck, 2010).

El presente estudio tuvo como objetivo caracterizar la composición y diversidad bacteriana en las cavidades oral y anal en relación al gremio alimenticio de los murciélagos en la Sierra Sur de Oaxaca, México, como el primer paso para abordar la ecología bacteriana en murciélagos.

\section{MATERIALES Y MÉTODOS}

Área de estudio: EL municipio de San Gabriel Mixtepec pertenece al Distrito de Juquila, Oaxaca, y cuenta con una superficie de $482.26 \mathrm{~km}^{2}$ y se ubica en las coordenadas geográficas $15^{\circ} 50^{\prime} 16^{\prime \prime} 13 " \mathrm{~N}-96^{\circ} 13^{\prime} 97^{\prime \prime} 15^{\prime \prime}$ $\mathrm{W}$, con altitudes que van de los 700 a los 1 300msnm (Canseco-Zorrilla, 2011). El clima presente en esta zona es el cálido sub-húmedo [Aw2 (w)] con lluvias en verano y un intervalo anual de temperatura de 22 a $28^{\circ} \mathrm{C}$ y una precipitación total anual de 1200 a $2500 \mathrm{msnm}$ (Canseco-Zorrilla, 2011). La vegetación dominante en la zona es la selva mediana subcaducifolia, caracterizada por presentar miembros de la familia Bombacaeae, Burseraceae, Leguminosae, Sapotaceae (Torres-Colín, 2004). En las partes más altas hay pequeñas franjas de bosque de pino y encino, y plantaciones de café en la mayor extensión del Cerro La Olla y Cerro Grande (Canseco-Zorrilla, 2011). De febrero a octubre 2012, se realizaron muestreos mensuales con una duración de cuatro noches consecutivas, empleando cuatro redes de niebla de $12 \mathrm{~m}$ de largo por $2.5 \mathrm{~m}$ de ancho, a una altura promedio de metro y medio a partir del nivel del suelo en cuatro sitios distintos. En cada sitio de muestreo se colocó una red y éstas se abrieron cinco horas durante el periodo de mayor actividad de los murciélagos (19:00-24:00h) con revisiones cada 45 minutos. Las redes se colocaron cerca de fuentes de agua, senderos hechos por humanos o animales dentro de la vegetación (Pérez-Irineo \& Santos-Moreno, 2010). De cada organismo capturado se tomaron muestras con hisopos estériles de las cavidades oral y anal, y los hisopos se depositaron en medios de pre-enriquecimiento (peptona de carne $10 \mathrm{~g}$ y cloruro de sodio $5 \mathrm{~g} / 100 \mathrm{~mL}$ ), y fueron almacenadas a $4^{\circ} \mathrm{C}$ por cinco días que duró el muestreo hasta ser analizadas.

\section{Aislamiento e identificación de bacte-} rias: En el laboratorio, los hisopos se descargaron a un medio de enriquecimiento (peptona de carne $5 \mathrm{~g}$, lactosa $4 \mathrm{~g}$, carbonato de calcio $10 \mathrm{~g} / 100 \mathrm{~mL})$ utilizando el método de estría simple (Michigan State University, 2014), dejándose a $30^{\circ} \mathrm{C}$ por $24 \mathrm{~h}$, se sembraron por estría simple en medios selectivos, diferenciales y cromogénicos, y se incubaron a temperaturas entre un rango de $30^{\circ} \mathrm{C}$ a $45^{\circ} \mathrm{C}$. Una vez obtenidas las cepas puras se identificaron por morfología macroscópica de las colonias, tinción de Gram (Fluka 94448, 94635, 90107), presencia de esporas y pruebas bioquímicas (prueba de cuagulasa, medio MIO, agar triple azúcar hierro, prueba OF, agar nutrient, agar 
bilis esculina, gelatina nutritiva, agar citrato de Simmons, agar DNasa con azul de toluidina, caldo base descarboxilasa Moeller, Agar lisina hierro, agar fenilalanina, agar urea de Christensen, medio de leche tornasolada, prueba deaminasa) (Bergey \& Holt, 1994).

Para conocer las especies bacterianas que coexisten en ambas cavidades y constituyen una comunidad, se elaboraron matrices de ausencia/presencia de taxones y matrices de abundancia de taxones (i.e. género y/o especie) para los organismos muestreados, y por cavidad muestreada; se estimaron los índices ecológicos de diversidad de Shanon-Wiener, el índice de diversidad de Margalef e índice de dominancia de Simpson (Moreno, 2001). Para comparar la diversidad y determinar si existe diferencia significativa entre los gremios y cavidades se utilizó la prueba t de Hutcheson $(\mathrm{p}<0.05)$. Para estimar la semejanza entre comunidades se utilizó el índice de Jaccard. Para los análisis estadísticos se usó el programa PAST (Hammer, Harper, \& Ryan, 2001). Con la finalidad de determinar el grado de similitud ecológica entre especies bacterianas y gremios alimenticios de murciélagos, así como en ambas cavidades, se utilizó el coeficiente de similitud de Jaccard, y se elaboró un dendrograma de similitud por medio de análisis de cluster con el programa PAST.

\section{RESULTADOS}

Durante el periodo de febrero a agosto 2012, se capturaron un total de 502 murciélagos frugívoros (Artibeus intermedius $\mathrm{n}=231$, Artibeus jamaicensis $\mathrm{n}=23$, Artibeus literatus $\mathrm{n}=6$, Centurio cenex $\mathrm{n}=9$, Dermanura phaeotis $\mathrm{n}=10$, Dermaunura tolteca $\mathrm{n}=70$, Sturnira lilium $\mathrm{n}=113$, Sturnira ludovici $\mathrm{n}=39$ ), 29 murciélagos hematófagos (Desmodus rotundus) y 11 murciélagos nectívoros (Glossophaga morenoi). Un total de 26 especies bacterianas fueron encontradas, el $42 \%$ perteneció a la división (filo) Firmicutes, y el 58\% a Proteobacterias; dentro de este último filo, el 53\% perteneció a la Familia Enterobacteriaceae y el resto entre las familias Pseudomonadaceae, Aeromonadaceae, Alcaligenaceae, Legionellaceae, Vibrionacea y Xanthomonadaceae. El $62 \%$ de las bacterias identificadas pertenecieron al grupo de las Gram -, mientras que el 38\% correspondieron al grupo de Gram + .

La diversidad más alta (3.178 bels naturales/individuo) y la mayor riqueza específica $\left(\mathrm{D}_{\mathrm{Mg}}=7.237\right)$ se registró en la región anal de los murciélagos hematófagos, donde la dominancia no excedió al 0.958 (Cuadro 1). La prueba $t$ de Hutcheson determinó que hay diferencia significativa entre la diversidad bacteriana de la región oral y anal de los individuos pertenecientes a los gremios frugívoros $(\mathrm{t}=-3.516$,

CUADRO 1

Datos de índices ecológicos para la comunidad bacteriana asociada a la región oral y anal de murciélagos durante el periodo de febrero a agosto 2012

TABLE 1

Data ecological indices for bacterial community associated with oral and anal cavity bats during the period February to August 2012

\begin{tabular}{lcccccc}
\multicolumn{1}{c}{ Índices/ cavidad } & \multicolumn{2}{c}{ Frugívoros } & \multicolumn{2}{c}{ Hematófagos } & \multicolumn{2}{c}{ Nectívoros } \\
& Oral & Anal & Oral & Anal & Oral & Anal \\
$\mathrm{S}$ & 8 & 22 & 10 & 24 & 6 & 14 \\
$\mathrm{H}^{\prime}$ (nats/ind.) & 2.079 & 3.091 & 2.303 & 3.178 & 1.792 & 2.639 \\
$\mathrm{D}_{\mathrm{Mg}}$ & 3.366 & 6.794 & 3.909 & 7.237 & 2.791 & 4.926 \\
$\mathrm{I}^{\prime}$ & 0.875 & 0.955 & 0.9 & 0.958 & 0.833 & 0.928 \\
\hline
\end{tabular}

$\mathrm{S}=$ riqueza de especies, $\mathrm{D}_{\mathrm{Mg}}=$ Riqueza específica de Margalef, $\mathrm{H}^{\prime}=$ Diversidad de Shannon-Weiner, $\mathrm{I}^{\prime}=$ Dominancia de Simpson.

$\mathrm{S}=$ species richness, $\mathrm{D}_{\mathrm{Mg}}=$ Wealth specified Margalef, $\mathrm{H}^{\prime}=$ Shannon-Weiner Diversity, I'=Simpson Dominance. 
g.l=14.761, $\mathrm{p}=0.003)$, hematófagos $(\mathrm{t}=-3.320$, g.l $=19.262, \mathrm{p}=0.003)$, y nectívoros $(\mathrm{t}=-2.497$, g.l $=11.933, p=0.026$ ).

Al comparar la diversidad bacteriana entre gremios, se observó que no existe diferencias significativas entre frugívoros $\mathrm{y}$ hematófagos $(\mathrm{t}=-0.344$, g.l $\mathrm{l}=16.797, \mathrm{p}=0.735)$, frugívoros y nectívoros $(\mathrm{t}=0.757$, g. $1=13.085$, $\mathrm{p}=0.482)$, nectívoros y hematófagos $(\mathrm{t}=1.096$, g.l=13.138, p=0.292), todos en la cavidad oral; frugívoros y hematófagos en la cavidad anal $(\mathrm{t}=0.206$, g. $1=46.919, \mathrm{p}=0.837)$; mientras que al comparar la cavidad anal de frugívoros y nectívoros $(\mathrm{t}=2.274, \mathrm{~g} . \mathrm{l}=29.660, \mathrm{p}=0.030)$, hematófagos y nectívoros en la cavidad anal $(\mathrm{t}=2.077$, g. $\mathrm{l}=29.904, \mathrm{p}=0.049)$, se encontraron diferencias significativas.

Las comunidades bacterianas más similares fueron las presentes en la cavidad anal de los gremios hematófago y frugívoros, con un índice de Jaccard de 0.692 (18 especies), seguido de la cavidad anal de nectívoros y frugívoros con 0.667 (14 especies), cavidad oral de nectívoros y frugívoros con 0.556 (5 especies), y por último, cavidad anal de hematófagos e nectívoros con 0.542 (13 especies, Fig. 1).
El diagrama de Venn nos permitió visualizar fácilmente las especies bacterianas que comparten los tres gremios alimenticios de los murciélagos en sus dos cavidades. En la cavidad oral observamos exclusividad de algunas especies como Bacillus cereus para nectívoros, Pseudomonas aeruginosa para frugívoros, y Aeromonas hydrophyla, Serratia marcescens, Staphylococcus aureus, S. epidermis, para los hematófagos, gremio que tuvo el mayor número de especies bacterianas (Fig. 2A). En la región anal, las bacterias específicas variaron ligeramente: los frugívoros tuvieron a Legionella pneumophila, los hematófagos a Acinetobacter lwoffii, A. hydrophyla, S. aureus, S. epidermis y $S$. marcescens, y los nectívoros no presentaron bacterias específicas (Fig. 2B).

\section{DISCUSIÓN}

Ojetti et al., 2009 reporta que en los mamíferos, incluyendo el humano, más del 99\% de su microbiota intestinal está compuesta por bacterias y estas se dividen en cuatro grandes filos: Firmicutes, bacteroidetes, Proteobacteria y Actinobacteria, En nuestro trabajo sólo

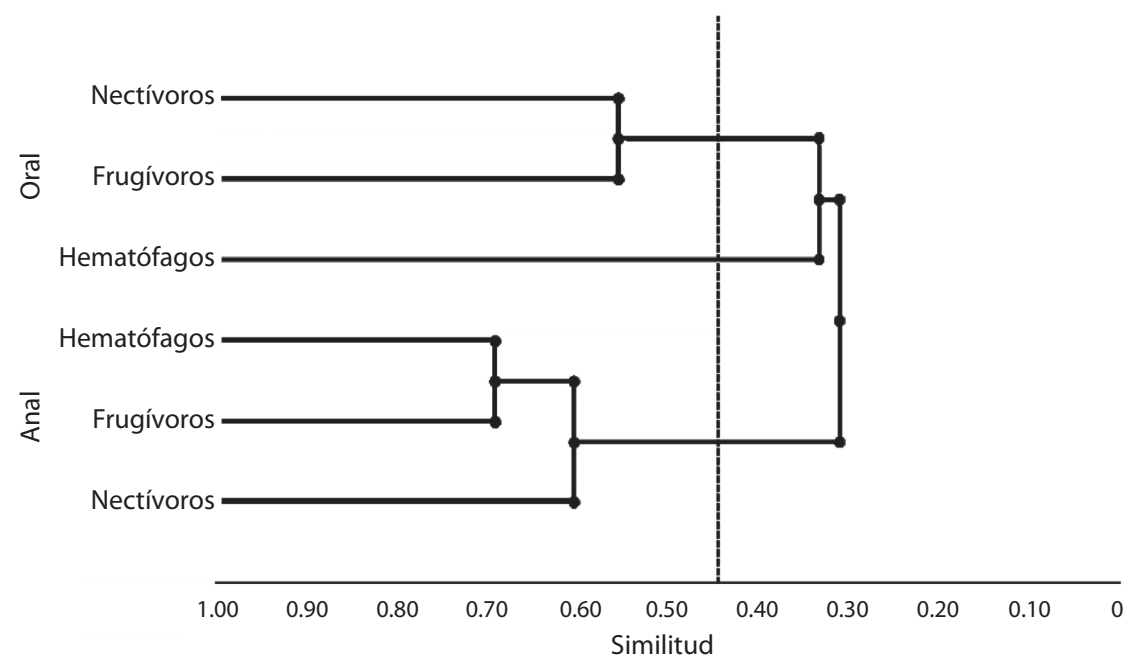

Fig. 1. Grado de similitud (Índice de Jaccard) de bacterias presentes entre las región oral y anal de murciélagos frugívoros, hematófagos y nectívoros.

Fig. 1. Degree of similarity (Jaccard index) of bacteria between oral and anal region of frugivorous, hematophagous and nectivorous. 

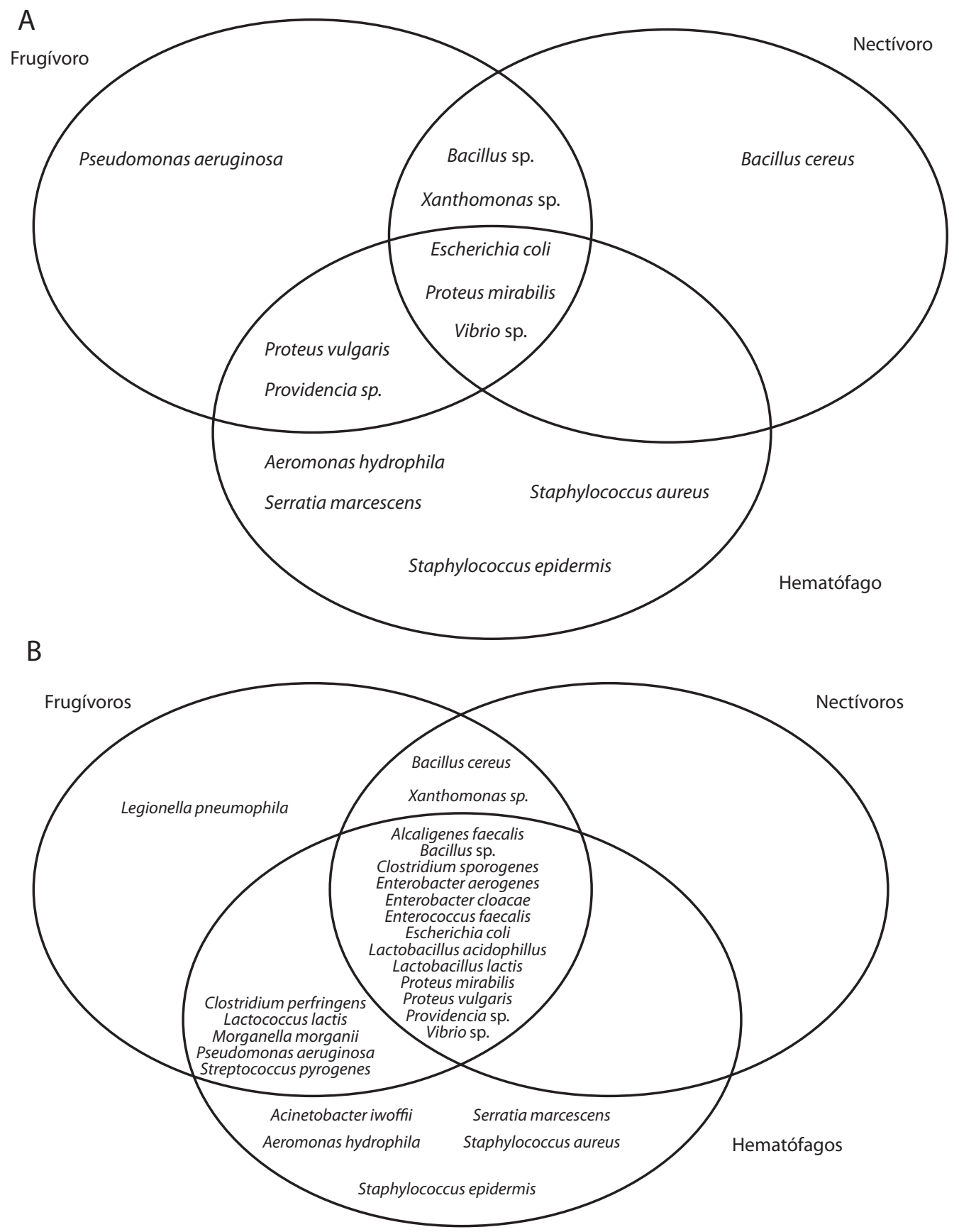

Fig. 2. Diagrama de Venn de los tres gremios alimenticios y sus especies bacterianas encontradas. A) Cavidad oral, B) Cavidad anal.

Fig. 2. Venn diagram of the three feeding guilds and bacterial species found. A) oral cavity, B) anal cavity. 
encontramos dos filos (Proteobacterias y Firmicutes), aunado con lo reportado por Chaverri (2006) en el tracto digestivo de Desmodus rotundus, Di Bella et al. (2003) en heces de murciélagos pertenecientes a las familias Vespertilionidae y Molossidae y Diane et al. (2013) en estómago e intestino de Cynopterus brachyotis brachyotis nos hace suponer que sólo firmicutes y proteobacterias forman parte de la microbiota intestinal en los murciélagos.

Por otro lado, se encontró diferencia entre microbiota y gremios siendo el de hematófagos más diverso, principalmente en la cavidad anal. Cabe resaltar que el presente trabajo es el primero que compara la diversidad bacteriana entre dos microhábitats (oral y anal) y gremios alimenticios. Existen trabajos previos enfocados en el aislamiento e identificación de la microbiota en heces (Di Bella et al., 2003) en intestino y estómago (Diane et al., 2013; Chaverri, 2006) de insectívoros, frugívoros y hematófagos, respectivamente. Estos estudios reportaron la presencia de especies bacterianas como B. cereus, Enterobacter cloacae, Enterococcus faecalis, Escherichia coli, Serratia marcescens, Pseudomonas aeruginosa, en el intestino y estómago de la especie frugívora Cynopterus brachyotis (Diane et al., 2013); Aeromonas hydrophila, Alcaligenes faecalis, Enterobacter cloacae, Enterococcus faecalis, Escherichia coli, Lactococcus lactis, Serratia marcescens, Staphylococcus aureus, Staphylococcus epidermidis, Proteus mirabilis, en el intestino y estómago de $D$. rotundus (hematófago). También Di Bella et al. (2003) encontró Acinetobacter calcoaceticus, Enterobacter cloacae, Escherichia coli, Proteus mirabilis, Proteus vulgaris, Streptococcus faecalis en heces de varias especies de nectívoros. Todas estas se consideran parte de la biota normal del tracto digestivo de mamíferos (Moreno et al., 1975; Pinus \& Müller, 1980).

Los murciélagos entre otros animales salvajes han sido implicados en los ciclos epidemiológicos de varias zoonosis emergentes y re-emergentes (Mühldorfer, 2013), sin embargo, poco se sabe de la simbiosis de estas bacterias en los murciélagos, aunque parece que los hábitos de alimentación pueden afectar a los tipos y la distribución de las bacterias en el tracto gastrointestinal (Anand \& Sripathi, 2004). Aunque se encontraron muchas bacterias que han sido reconocidas como agente causal de muchas enfermedades que afectan al humano y otros animales (Mühldorfer, 2013), estas pudieran ser autóctonas de los murciélagos y jugar un papel de mutuo beneficio, proveyéndole el hospedero condiciones estables de crecimiento y nutrientes suplementarios, mientras que la microbiota contribuye en: la nutrición del hospedero, desarrollo del sistema inmune, estabiliza la población microbiana y prohibe la colonización de patógenos. Como es el caso de E. coli que estuvo presente en los tres gremios, lo que nos hace suponer que es parte de la biota normal de los murciélagos, dicha bacteria es una de la más comunes en el tracto intestinal de vertebrados, ya que juega un papel importante en la síntesis de algunas vitaminas ( $\mathrm{B}, \mathrm{K}, \mathrm{C})$, así como prevenir la colonización de otros microorganismos en el tracto intestinal por medio de componentes antimicrobianos como las colicinas (Barnes, Sidhu, \& Gordon, 2007). Numerosos factores están implicados en el control de la estabilidad de la microbiota del intestino tales como el $\mathrm{pH}$ intestinal, la temperatura, la interacción microbiana, el peristaltismo, ácido biliar, terapia con fármacos y la respuesta inmune (Ojetti et al., 2009). Cuando estos mecanismos fallan, puede ocurrir un desequilibrio de la microflora intestinal (Ojetti et al., 2009).

La especificidad de bacterias en algunos gremios como: Bacillus cereus, Bacillus sp. Xanthomonas sp. en nectívoros y frugívoros se puede explicar de la siguiente manera. Bacillus cereus se ha reportado que causa diarrea $\mathrm{y}$ dolor abdominal inducida por una enterotoxina (Drobniewski, 1993), pero también se ha visto que tiene una importancia ecológica en la degradación de celulosa y xilano (Anand, Chattopadhyay, \& Kandula, 2012), por lo que se pudiera inferir que ayudan en la digestión de los xilanos y celulosas solubles en su dieta. Mientras Xanthomonas es considerado 
un fitopatógeno y probablemente el murciélago juegue un papel de dispersor del patógeno.

Para los hematófagos mostraron especificidad por Aeromonas hydrophyla, Serratia marcescens, Staphylococcus aureus, S. epidermis, Pseudomonas aeruginosa, es probable que al tipo de dieta que llevan tengan algo que ver (Ley et al., 2008; Louis, Scott, Duncan, \& Flint, 2007; Whitaker et al., 2004; Gibbons, 1984; Muller, Pinus, \& Schmidt, 1980). Aeromonas hidrophyla es considerada de importancia clínica ya que produce una enterotoxina que puede provocar daños tisulares, pero en murciélagos pudiera ser un endosimbiótico anticoagulante que le permite digerir glóbulos rojos (Snower, Ruef, Kuritza, \& Edberg, 1989). Serratia marcescens puede causar conjuntivitis, queratitis, infecciones respiratorias, meningitis y endocarditis en humanos, pero también se ha visto que $S$. marcescens tiene una proteína extracelular de unión al grupo hemo- has A, lo que permite la liberación del grupo hemo de la hemoglobina y así adquirir el hierro necesario para su metabolismo (Latoff, Ghigo, \& Wandersman, 1994). Staphylococcus aureus es reconocido como un importante patógeno en el ser humano y animales (vacas, perros, gatos, pollos) causándoles desde infecciones cutáneas leves hasta causar la muerte por bacteriemia, por otro lado, S. aureus produce varios exoenzimas que se cree que tienen un efecto sustancial en la patogénesis de la infección por estafilococos, dentro de ellas está la estafiloquinasa (Kuusela \& Saksela, 1990), una proteína que puede activar el plasminógeno (glicoproteína presente en el plasma sanguíneo, que cuya función es la disolución de coágulos) y pudiera ayudar a los hematófagos durante su alimentación. En 1989 fue encontrado este activador de plasminégeno por Gardell et al., en saliva de estos animales. La subsistencia de los hematófagos en una dieta de sangre fresca aparentemente depende de su capacidad para interferir con el sistema hemostático del donante de sangre. Es probable que la riqueza y la diversidad bacteriana presentes en la cavidad oral de murciélagos hematófagos se justifiquen pensando que estas bacterias pudieran contener una gran variedad de factores que actúen para mantener sangrados prolongados en la mordedura y preservar la fluidez de la sangre tras la ingestión. Algunas bacterias específicas pertenecientes al tracto digestivo pudieran tener una relación en el metabolismo, captura de nutrientes y vitaminas que son eliminadas por heces, por lo tanto las encontramos en la cavidad anal.

La presencia de Legionella pneumophila en el gremio de frugívoros (Artibeus jamaicensis) puede ser al agua o alimentos contaminados por esta bacteria o a través de otros murciélagos. Bacterias como L. pneumophila que es una bacteria Gram -, son de interés zoonótico, ya que causa la enfermedad del legionario o legionelosis (Cohen, Boldur, Tamarin-Landau, \& Sompolinsky, 1986).

Los resultados del presente trabajo comparan por primera vez la diversidad bacteriana entre dos cavidades (oral y anal) y entre gremios alimenticios. Nos permitió determinar que las bacterias encontradas se consideran parte de la biota normal del tracto digestivo de mamíferos. En este trabajo como en muchos otros, se han encontrado bacterias a las cuales se les reconoce como agente causal de muchas enfermedades que afectan al humano y otros animales, pero falta información sobre la relación simbiótica entre la biota en la cavidad oral y anal, ya que estas pudieran ser autóctonas de los murciélagos y jugar un papel de mutuo beneficio, específicamente degradando compuestos de la dieta, la producción de alimentos y el desarrollo y mantenimiento de la inmunidad mucosa normal. Al entender la importancia de la relación entre el hospedero y su población bacteriana, pueden ayudar a mejorar los esfuerzos de conservación que se vienen realizando para proteger especies como los murciélagos.

\section{AGRADECIMIENTOS}

Agradecemos al PROMEP por el financiamiento otorgado al Cuerpo Académico Comunidades Bióticas de la Universidad del Mar (CUP: 2IR1112). Asimismo, agradecemos al Rancho El Sagrado las facilidades y la hospitalidad para realizar el presente trabajo. 


\section{RESUMEN}

Los estudios sobre ecología bacteriana de la microbiota en los murciélagos son limitados, dicha información es importante para determinar la importancia de esta interacción entre microbiota y hospedero, por tal motivo el objetivo de este trabajo es caracterizar la composición y diversidad bacteriana en las regiones orales y anales de 10 especies de quirópteros con relación al gremio alimenticio a través de medios selectivos, cromogénicos y pruebas bioquímicas. Se muestrearon 502 murciélagos frugívoros, 29 hematófagos y 11 nectívoros, fueron encontradas un total de 26 especies bacterianas, siendo predominantes el filo proteobacterias y la familia Enterobacteriaceae. Se observaron diferencias estadísticamente significativas entre el microhabitat oral y anal [frugívoros $(\mathrm{t}=-3.516, \mathrm{~g} .1=14.761$, $\mathrm{p}=0.003)$, hematófagos $(\mathrm{t}=-3.320, \mathrm{~g} .1=19.262, \mathrm{p}=0.003)$, y nectívoros $(\mathrm{t}=-2.497$, g.l $=11.933, \mathrm{p}=0.026)$, así como en algunos gremios (frugívoros e nectívoros en la región anal $(\mathrm{t}=2.274$, g.l $=29.660, \mathrm{p}=0.030)$, hematófago y nectívoros en la región anal $(\mathrm{t}=2.077$, g.l=29.904, p=0.049)]. También se mostró que existe especificidad de bacterias en algunos gremios como: Bacillus cereus, B. spp. X. spp. en nectívoros y frugívoros, así como, Pseudomonas aeruginosa, Serratia marcescens, Staphylococcus aureus, S. epidermis, Aeromonas hydrophyla en hematófagos que podría deberse al tipo de dieta que llevan o por transferencia de bacterias al contacto con sus presas. Los murciélagos han sido relacionados con varias zoonosis, sin embargo poco se conoce sobre la relación que existe entre el murciélago, su microbiota y la dieta que llevan. Estas bacterias pudieran ser autóctonas de los murciélagos y jugar un papel de mutuo beneficio, proveyéndole al hospedero condiciones estables de crecimiento y nutrientes complementarios, mientras que la microbiota contribuye en la nutrición del hospedero, desarrollo del sistema inmune, estabilizando la población microbiana y prohibiendo la colonización de patógenos. Entender la importancia de la relación entre el hospedero y su población bacteriana puede ayudar a mejorar los esfuerzos de conservación que se vienen realizando para proteger especies como los murciélagos.

Palabras clave: Quirópteros, frugívoros, hematófagos, nectívoros, diversidad bacteriana, microbiota.

\section{REFERENCIAS}

Anand, A. A., Chattopadhyay, B., \& Kandula, S. (2012). Isolation and Characterization of Cellulose-Degrading and Xylanolytic Bacteria from the Short-Nosed Fruit Bat Cynopterus sphinx. Acta Chiropterologica, 14(1), 233-239.

Anand, A. A. \& Sripathi, K. (2004). Digestion of cellulose and xylan by symbiotic bacteria in the intestine of the Indian flying fox (Pteropus giganteus). Comparative Biochemistry and Physiology, 139, 65-69.
Barnes, B., Sidhu H., \& Gordon, D. M. (2007). Host gastro-intestinal dynamics and the frequency of colicin production by Escherichia coli. Microbiology, 153, 2823-2827.

Bergey, D. H. \& Holt, J. G. (1994). Bergey's Manual of Determinative Bacteriology. USA: Lippincott Williams and Wilkins.

Canseco-Zorrilla, E. (2011). Estudio de la diversidad de macromicetos silvestres en el municipio de San Gabriel Mixtepec, Oaxaca (Tesis Licenciatura, Universidad del Mar, Puerto Escondido, Oaxaca). Recuperado de http://www.umar.mx/tesis_PE/ Tesis_Digitales/Canseco\%20Zorilla\%20Eduviges/ Estudio\%20de\%201a\%20diversidad $\% 20$ de $\% 20$ macromicetos $\% 20$ silvestres $\% 20$ en $\% 20 \mathrm{el} \% 20$ Municipio $\% 20$ de $\% 20$ San $\% 20$ Gabriel\%20Mixtepec. $\% 20$ Eduviges\%20Canseco\%20zorrilla.pdf

Cohen, A., Boldur, I., Tamarin-Landau, R., \& Sompolinsky, D. (1986). Legionellosis in animals in Israel. Israel Journal of Medical sciences, 22(9), 674-677.

Chaverri, G. (2006). Flora bacteriana aeróbica del tracto digestivo del vampiro común, Desmodus rotundus (Chiroptera: Phyllostomidae). Revista Biología Tropical, 54(3), 717-724.

Diane, S. D., Nga, Y. K., Chuaa, E. L., Arumugama, Y., Wonga, W. L., \& Kumaranb, J. V. (2013). Isolation and identification of gastrointestinal microbiota from the short-nosed fruit bat Cynopterus brachyotis brachyotis, Microbiological Research, 168(8), 485-496.

Di Bella, C., Piraino, C., Caracappa, S., Fornasari, L., Violani, C., \& Zara, B. (2003). Enteric microflora in Italian Chiroptera. Journal Mountain Ecology, 7, 221-224.

Drobniewski, F. A. (1993). Bacillus cereus and related species. Clinical Microbiology Reviews, 6(4), 324-338.

Gardell, S. J., Duong Le, T., Diehl, R. E., York, J. D., Hare, T. R., Register, R. B., Jacobs, J. W., Dixon, R. A. F., \& Friedman, P. A. (1989). Isolation, Characterization, and cDNA Cloning of a Vampire Bat Salivary Plasminogen Activator. The Journal of Biological Chemistry, 264(30), 17947-17952.

Gibbons, R. J. (1984). Microbial Ecology Adherent Interactions Which May Affect Microbial Ecology in the Mouth. Journal of Dental Research, 63, 378-385.

Hammer, Ø. D. A., Harper, T., \& Ryan, P. D. (2001). PAST: Paleontological statistics software package for education and data analysis. Paleontología Electronica, 4(1), 9 .

Jablonski, L. (1979). Podstawy mikrobiologii lekarskiej. Warszawa: PWL.

Klite, P. D. (1965). Intestinal bacteria flora and transit time of three neotropical bat species. Journal of Bacteriology, 90, 375-379. 
Kunz, T. H. \& Brock, F. (2006). Bat Ecology. USA: The University of Chicago Press.

Kuusela, P. \& Saksela, O. (1990). Binding and activation of plasminogen at the surface of Staphylococcus aureus Increase in affinity after conversion to the Lys form of the ligand. European Journal of Biochemistry, 193, 759-765.

Latoff, S., Ghigo, J. M., \& Wandersman, C. (1994). Iron acquisition from heme and hemoglobin by a Serratia marcescens extracellular protein. Microbiology, 91, 9876-9880.

Ley, R. E., Hamady, M., Lozupone, C., Turnbaugh, P. J., Ramey, R. R., Bircher, J. S., Schlegel, M. L., Tucker, T. A., Schrenzel, M. D., Knight, R., \& Gordon, J. I. (2008). Evolution of Mammals and Their Gut Microbes. Science, 320(5883), 1647-1651.

Louis, P., Scott, K. P., Duncan, S. H., \& Flint, H. J. (2007). Understanding the effects of diet on bacterial metabolism in the large intestine. Journal of Applied Microbiology, 102(5), 1197-208.

Moreno, C. (2001). Métodos para medir la biodiversidad. M\&T Manuales y Tesis SEA. doi: http://entomologia. rediris.es/sea/manytes/metodos.pdf

Moreno, G., Lopes, C. A. M., Seabra, E., Pavan, C., \& Correa, A. (1975). Bacteriological study of the intestinal flora of Desmodus rotundus. Arquivos do Instituto Bioliologico (São Paulo), 42, 229-232.

Michigan State University. (2014). The streak plate method. Recuperado de http://learndat.tech.msu.edu/sites/ default/files/showcase/Streak_plate/streak_plate.html

Mühldorfer, K. (2013). Bats and Bacterial Pathogens: A Review. Zoonoses and Public Health, 60, 93-103.

Mühldorfer, K, Wibbelt, G., Haensel, J., Riehm, J., \& Speck, S. (2010). Yersinia species isolated from bats, Germany. Emerging Infectious Diseases Journal, 16, 578-80.
Muller, H. E., Pinus, M., \& Schmidt, U. (1980). Aeromonas hydrophila as a normal intestinal bacterium of the vampire bat (Desmodus rotundus). Zentralblatt fur Veterinarmedizin, 27(5), 419-424.

Ojetti, V., Gigante, G., Ainora, M. E., Fiore, F., Barbaro, F., \& Gasbarrini, A. (2009). Microflora imbalance and gastrointestinal diseases. Digestive and Liver Disease, 3, 35-39.

Pérez-Irineo, G. \& Santos-Moreno, J. A. (2010). Diversidad de una comunidad de mamíferos carnívoros en una selva mediana del noreste de Oaxaca, México. Acta Zoológica Mexicana (nueva serie), 26(3), 721-736

Pinus, M. \& Müller, H. E. (1980). Enterobacteria of bats (Chiroptera). Zentralbl Bakteriol, 247(3), 315-22.

Snower, D. P., Ruef, C., Kuritza, A. P., \& Edberg, S. C. (1989). Aeromonas hydrophila infection associated with the use of medical leeches. Journal of Clinical Microbiology, 27, 1421-22.

Souza, V., Rocha, M., Valera, A., \& Eguiarte, L. E. (1999). Genetic structure of natural populations of Escherichia coli in wild hosts on different continents. Applied and Environmental Microbiology, 65, 3373-3385.

Torres-Colín, R. (2004). Tipos de vegetación. In A. J. García-Mendoza, M. J. Ordoñez, \& M. A. BrionesSalas (Eds.), Biodiversidad de Oaxaca (pp. 105-117). México: UNAM-Fondo Oaxaqueño para la Conservación de la Naturaleza-World Wildlife Fund.

Voigt, C., Caspers, B., \& Speck, S. (2005). Mammalogists Bats, Bacteria, and Bat Smell: Sex-Specific Diversity of Microbes in a Sexually Selected ScentOrgan. Journal of Mammalogy, 86(4), 745-749.

Whitaker, J. O., Dannelly Jr., H. K., \& Prentice, D. A. (2004). Chitinase in insectivorous bats. Journal of Mammalogy, 85(1), 15-18. 
